\title{
Boviolles
}

Oppidum de Châtel

\section{Thierry Dechezleprêtre}

\section{(2) OpenEdition \\ 12 Journals}

Édition électronique

URL : http://journals.openedition.org/adlfi/8666

ISSN : 2114-0502

Éditeur

Ministère de la culture

Référence électronique

Thierry Dechezleprêtre, "Boviolles », ADLFI. Archéologie de la France - Informations [En ligne], Lorraine, mis en ligne le 01 mars 2001, consulté le 03 mai 2019. URL : http://journals.openedition.org/ adlfi/8666

Ce document a été généré automatiquement le 3 mai 2019.

(c) Ministère de la Culture et de la Communication, CNRS 


\title{
Boviolles
}

\author{
Oppidum de Châtel
}

Thierry Dechezleprêtre

\author{
Identifiant de l'opération archéologique : F1355200100040 \\ Date de l'opération : 2001 (PT)
}

1 L'enceinte de Châtel à Boviolles fait l'objet, depuis 1998, d'un programme de recherches visant à l'étude de l'organisation et de la chronologie de cet important oppidumdes Leuques implanté à proximité directe de la vaste agglomération antique de Nasium. La superficie du site - plus de 50 ha - et la complexité de ce type d'habitat ont nécessité la mise en place de méthodes diverses d'investigation archéologique. En 1998, le département de géophysique appliquée de l'université de Jussieu a réalisé une première prospection magnétique de manière à évaluer l'apport des méthodes géophysiques à la connaissance de l'organisation interne de l'oppidum.

2 Sur la base de la cartographie des anomalies, des sondages archéologiques ont été menés en 2001 de manière à caractériser le type de vestiges présents et à évaluer leur état de conservation.

3 Les trois sondages linéaires, implantés de manière à recouper les différentes anomalies repérées par les prospections magnétiques, ont mis en évidence la présence de nombreux vestiges en creux qui se succèdent en chronologie relative, de La Tène D1 à l'époque augustéenne. Le sondage 1 a livré toutefois quelques rares indices d'une fréquentation à La Tène $\mathrm{C} 2$ ou au début de La Tène D1. L'élément structurant majeur est constitué par un fossé de $7 \mathrm{~m}$ à $8 \mathrm{~m}$ de large qui semble isoler la partie supérieure de l'oppidum. Son tracé n'est actuellement connu, par les différentes prospections géophysiques et aériennes, que dans la moitié nord de l'enceinte, sur un développement total d'environ $1000 \mathrm{~m}$. Les deux coupes réalisées révèlent que sa forme générale évolue entre un profil en $\mathrm{V}$ et un profil en $\mathrm{U}$ très ouvert. La profondeur conservée sous le niveau de décapage est d'environ 1,20 m. La coupe stratigraphique comme le remplissage de ce fossé indiquent qu'il a été utilisé comme un fossé ouvert. Cependant, aucune trace d'un éventuel talus n'a pu être 
clairement mise en évidence. Seul le profil du sondage 2 suggère que le flanc tourné vers l'intérieur de l'enceinte, au sud, ait été protégé par la masse d'un talus. Les données stratigraphiques suggèrent deux phases de comblement rapide, qu'il s'agisse de dépôts primaires de type dépotoir avec apport rapide, ou de remblais volontaires. Le mobilier associé, caractérisé par un fort taux de fragmentation, offre un faciès dont les éléments les plus récents peuvent être datés du changement d'ère. Cette chronologie est confirmée par la fosse FS 2020, creusée dans les couches supérieures de remplissage du fossé. Le mobilier céramique, et notamment des fragments de gobelets à paroi fine pouvant appartenir aux productions de Lyon, permet de disposer d'un terminus ante quempour le comblement final du fossé.

4 Les structures comprises dans l'espace délimité par ce fossé se caractérisent par leur nature très variée. Si quelques trous de poteaux ont été mis en évidence, la largeur de la fenêtre de sondage n'a par permis d'appréhender de plan complet. Quant aux fosses, de forme circulaire ou ovale, elles correspondent majoritairement à des fosses d'extraction de matériaux. Des niveaux de circulation ont également pu être mis en évidence. Dans le sondage 1 , un niveau de sol scellé par un remblai stérile a pu être observé sur environ $30 \mathrm{~m}^{2}$. Il a livré notamment quelques éléments de faune en connexion, des fragments d'amphores vinaires italiques (Dressel 1), des fragments de grande rouelle et de bracelet jonc en alliage cuivreux, ainsi qu'un fragment de bracelet en verre pouvant être daté de La Tène $\mathrm{C}$.

5 Le sondage 2 a révélé, quant à lui, la présence de niveaux d'empierrements d'une dizaine de mètres de large. Ces niveaux se développent selon un axe parallèle au fossé A1, à une quinzaine de mètres de celui-ci. Leur organisation, et notamment la présence de dalles de calcaire et d'un gravier sur l'état 2 (SL 2014), évoque les techniques de mise en œuvre des voies, telle qu'elles ont été observées sur d'autres sites contemporains. L'ensemble des observations archéologiques convergent pour interpréter ces niveaux d'empierrements comme un aménagement de type urbain, pouvant correspondre à un élément de voirie. Considérant la taille des sondages réalisés, il ne s'agit cependant que d'une hypothèse.

Ces empierrements étaient scellés par un niveau très organique qui varie de $0,20 \mathrm{~m}$ à $0,30 \mathrm{~m}$ d'épaisseur. Il s'agit d'un niveau homogène, non stratifié, riche en matière organique et en artefacts archéologiques. L'état de conservation de ce matériel, et notamment de la faune, exclu qu'il puisse s'agir d'un niveau de circulation et encourage donc l'hypothèse d'un remblai d'origine hétérogène. Le mobilier présent au sein de cette couche présente un spectre chronologique couvrant l'ensemble de La Tène D2 et vraisemblablement le début de la phase suivante :amphores de type Dressel 1B, lot de céramiques à vernis noir (campanienne $\mathrm{C}$ ), 1 fragment de bracelet violet à section triangulaire. Le faciès des fibules est cohérent avec cette chronologie centrée sur La Tène D2 (1fibule à arc rubané, et 1 fibule à arc coudé et coquille) avec toutefois quelques éléments plus anciens (1 fibule à pied rattaché à l'arc, 2 fibules à arc tendu). 
INDEX

Index géographique : Lorraine, Meuse (55), Boviolles

Index chronologique : âge du Fer

operation Prospection thématique (PRT)

Thèmes : bracelet, céramique campanienne, dépotoir, fibule, oppidum, prospection

géophysique, remblai, stratigraphie, trou de poteau, verrerie, voirie

\section{AUTEURS}

\section{THIERRY DECHEZLEPRÊTRE}

MUS 